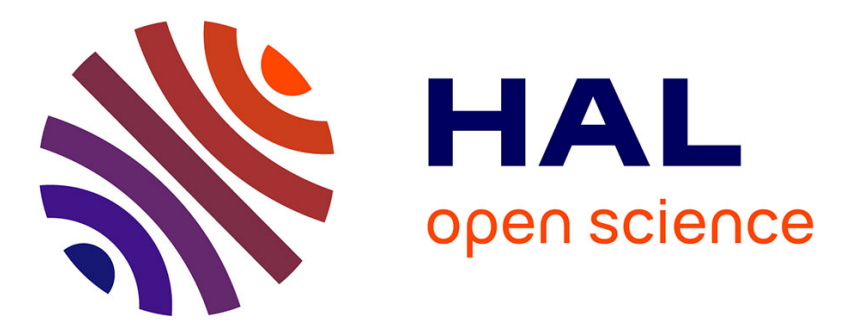

\title{
Occupation and lymphoid malignancies: results from a French case-control study.
}

\author{
Laurent L. Orsi, Xavier X. Troussard, Alain A. Monnereau, Christian C. \\ Berthou, Pierre P. Fenaux, Gerald G. Marit, Pierre Soubeyran, Françoise F. \\ Huguet, Noel Milpied, Michel M. Leporrier, et al.
}

\section{To cite this version:}

Laurent L. Orsi, Xavier X. Troussard, Alain A. Monnereau, Christian C. Berthou, Pierre P. Fenaux, et al.. Occupation and lymphoid malignancies: results from a French case-control study.. Journal of Occupational and Environmental Medicine, 2007, 49 (12), pp.1339-50. 10.1097/JOM.0b013e3181569a49 . inserm-00239464

\section{HAL Id: inserm-00239464 https://www.hal.inserm.fr/inserm-00239464}

Submitted on 5 Feb 2008

HAL is a multi-disciplinary open access archive for the deposit and dissemination of scientific research documents, whether they are published or not. The documents may come from teaching and research institutions in France or abroad, or from public or private research centers.
L'archive ouverte pluridisciplinaire $\mathbf{H A L}$, est destinée au dépôt et à la diffusion de documents scientifiques de niveau recherche, publiés ou non, émanant des établissements d'enseignement et de recherche français ou étrangers, des laboratoires publics ou privés. 


\section{HAL author manuscript}

L Orsi, X Troussard, A Monnereau, C Berthou, P Fenaux, G Marit, P Soubeyran, F Huguet, N Milpied, M Leporrier, D Hemon, J Clavel

\section{Correspondence to:}

Laurent ORSI, MS

Inserm U754

16, av. Paul Vaillant-Couturier

F-94807 VILLEJUIF Cedex;

Paris-Sud University,

UMR-S754, IFR69,

F-94800 Villejuif, France

phone : 33145595028

fax : 33145595151

mail : orsi@vjf.inserm.fr

\section{Authors' affiliations}

Xavier Troussard, MD, Côte de Nacre Hospital, Caen, France

Alain Monnereau, MD, INSERM, U754, F-94800 Villejuif, France; Paris-Sud University, UMR-S754, IFR69, F-94800

Villejuif, France ; Bergonié Institute, Comprehensive cancer center, Bordeaux, France

Christian Berthou, MD, Morvan Hospital, Brest, France

Pierre Fenaux, MD, Avicenne Hospital, Bobigny, France

Gerald Marit, MD, Haut-Lévêque Hospital, CHU Bordeaux, Pessac, France

Pierre Soubeyran, MD, Bergonié Institute, Comprehensive cancer center, Bordeaux, France

Françoise Huguet, MD, Purpan Hospital, Toulouse, France

Noel Milpied, MD, Hôtel Dieu Hospital, Nantes, France

Michel Leporrier, MD, Côte de Nacre Hospital, Caen, France

Denis Hemon, PhD, INSERM, U754, F-94800 Villejuif, France; Paris-Sud University, UMR-S754, IFR69, F-94800 Villejuif, France

Jacqueline Clavel, MD PhD, INSERM, U754, F-94800 Villejuif, France ; Paris-Sud University, UMR-S754, IFR69, F94800 Villejuif, France

Running title: Occupation and lymphoma

Keywords: occupational exposure, farming, risk, lymphoma, case-control study; epidemiology

\section{Funding}

This work was supported by grants from the Association pour la Recherche contre le Cancer, the Fondation de France, and AFSSET, and a donation from Faberge employees. 


\section{Abstract}

Objectives: Investigating relationships between potential occupational risk factors and lymphoid malignancy (LM).

Methods: We conducted a multicenter hospital-based case-control study in France between 2000-2004, including 824 incident cases of non-Hodgkin's lymphoma (NHL), Hodgkin's lymphoma (HL), multiple myeloma (MM) and 'lymphoproliferative syndrome' (LPS) and 752 frequency-matched controls. Data were collected through face-to-face standardized and detailed interviews.

Results: Farming was significantly associated with NHL (OR=1.4 [1.0-2.0]) and, although not significantly, with LPS and MM. ORs were higher for longest durations of exposure. Self-declared exposure to pesticides was significantly associated with $\mathrm{NHL}(\mathrm{OR}=1.8$ [1.2-2.7]) and $\mathrm{HL}(\mathrm{OR}=2.2$ [1.0-4.7]). Neither solvent-related jobs nor self-reported exposure to solvents were related to LM. Systematic screening based on job titles did not evidence any other association.

Conclusions: The results support the hypothesis that farming plays a role in most types of LM. 


\section{INTRODUCTION}

The expression 'lymphoid malignancies' (LM) covers various diseases affecting lymphoid tissue, namely: Hodgkin's lymphoma (HL), non-Hodgkin's lymphoma (NHL), multiple myeloma (MM) and lymphoproliferative syndrome (LPS). In France, LM are the most frequent cancers after smoking-related cancer and the number of incident LM cases was estimated to be approximately 17,000 in 2000 . The annual number of deaths was almost 9,000.(1) In recent decades, the incidence of $\mathrm{NHL}$ has dramatically increased in almost all industrialized countries $(2,3)$ and data from the French registries show a yearly rate of increase that was greater than 3\% (3.8\% in men, 3.5\% in women) between 1978 and 2000.(1) The causes of the increase in NHL remain largely unexplained. The increase began before the AIDS epidemic and does not seem to be fully explained by changes in diagnostic methods or registration. $(3,4)$ Changes in lifestyle and occupation are thus expected to play a role in the increase.

The etiology of LM remains largely unknown, except for a few established risk factors. Thus, congenital and acquired immunodeficiencies are well documented predisposing factors for $\mathrm{NHL} ;(5)$ infection by Epstein Barr virus (EBV) is strongly related to Burkitt's lymphoma and $\mathrm{HL} ;(6)$ and Helicobacter pylori infections are associated with MALT lymphoma.(7) Malaria has been identified as a cofactor of EBV-induced Burkitt's lymphoma in Africa, but the other cofactors, particularly in western countries, have yet to be discovered. In addition to the known risk factors, occupational exposures, particularly in agriculture-related jobs, are strongly suspected of being risk factors for LM.

Numerous studies have investigated for an association between farming and NHL. The case-control studies conducted in the USA,(8-13) Italy,(14-16) France(17) and Spain,(18) have almost all reported some degree of positive association with farming. A meta-analysis estimated that the excess $\mathrm{NHL}$ risk associated with farming was weak, but slightly more marked in the USA.(19)

MM has also been shown to be associated with farming-related jobs(14, 20-24) and possibly with glyphosate application.(25) For LPS, the association has been less well documented. Nonetheless, a French study(26) and a Swedish study(27) have reported associations between hairy cell leukemia, a rare LPS entity, and farming. Farmers are subject to a variety of exposures, including solvents, various organic antigens, microbial infections and pesticides. Several pesticides have been found to be associated with increased LM risk, including carbamates,(28-30) and organophosphates, $(31,32)$ as have phenoxyacetic acid herbicides, $(29,30,33,34) \operatorname{DDT}(30,34,35)$ and organochlorine insecticides, aldrin,(30) dieldrin,(12) chlordane,(9) lindane(30, 36, 37) and toxaphene.(12)

This study investigated the role of lifelong occupations in the occurrence of the main ICD-O categories of LM using data from a large-scale, multicenter, case-control study. 


\section{MATERIALS AND METHODS}

\section{Study population}

A French multicenter hospital-based case-control study was conducted in the main hospitals of Bordeaux, Brest, Caen, Nantes, Lille and Toulouse from September 2000 to December 2004. The eligible cases were incident cases with a diagnosis of lymphoid malignancy (LM), aged between 18 and 75 years, and residing in the hospital catchment area of each center. The diagnosis of LM was documented by cytology and histology, and reviewed by a team of pathologists. All cases were classified using the WHO classification (ICD-O-3). Cases treated with immunosuppressant drugs and cases with AIDS were not eligible. Except for the LPS cases, who were included up to 18 months post-diagnosis in view of the good prognosis, all cases had to be recruited within 6 months of diagnosis. Most cases $(88.9 \%)$ were included within 3 months. Of the 872 subjects eligible during the recruitment period, 48 (5.5\%) refused to participate. The study population thus consisted in 824 incident cases of LM, classified using ICD-O-3, and further subdivided into four categories: HL ( $n=$ 149, ICD-O-3 codes (9650-9655/3, 9659/3, 9661-9665/3, 9667/3)), NHL ( $\mathrm{n}=399$ consisting of 173 cases of diffuse large B cell-lymphoma (DLCL) (9679/3, 9680/3), 101 cases of follicular lymphoma (FL) (9690/3, 9691/3, 9695/3, 9698/3), 21 cases of lymphoplasmacytic lymphoma/Waldenstrom macroglobulinemia (9671/3, 9761/3), 17 cases of marginal zone Bcell lymphoma of the MALT type (9699/3), 3 cases of splenic marginal zone B-cell lymphoma (9689/3), 25 cases of T-cell lymphoma $(9702 / 3,9705 / 3,9714 / 3,9729 / 3), 25$ cases of mantle-cell lymphoma (9673/3), and 34 cases of other Iymphoma $(9728 / 3,9687 / 3,9826 / 3,9591 / 3)), M M(n=108,(9731-9732 / 3))$ and LPS $(n=168,132$ cases of chronic lymphocytic leukemia (CLL) $(9823 / 3,9670 / 3)$ and 36 cases of hairy cell leukemia (HCL) (9940/3)).

The hospital-based design of the study was chosen since case and control blood samples were required. Special care was therefore paid to selecting an appropriate control group. The controls were patients with no prior history of hematological malignancy recruited in the same hospitals as the cases, mainly in orthopedic and rheumatological departments. Subjects admitted for cancer or a disease directly related to occupation (occupational injuries), smoking (chronic obstructive pulmonary disease, ischemic cardiovascular disease) or alcohol consumption (alcoholic cirrhosis) were not eligible as controls in order to avoid over-representation of some of the factors of interest. The controls were individually matched with the cases by center, age ( \pm 3 years) and gender. The aim of matching was to ensure that at least one control would be available for each case. Out of the 853 eligible controls identified during the recruitment period, 100 refused the interview (11.7\%) and 1 subject whose interview was incomplete was excluded a posteriori. The final control sample thus consisted of 752 subjects. The reasons for hospital admission of the controls were mainly orthopedic or rheumatological (fractures $(19.9 \%)$, wounds $(0.9 \%)$, other non-occupational injuries $(10.8 \%)$, osteoarthritis $(23.3 \%)$, back diseases (15.3\%), polyarticular diseases $(4.0 \%)$, infectious bone and joint diseases $(2.9 \%)$, minor musculoskeletal malformations (4.8\%), other diseases of the bones and joints $(6.2 \%))$, peripheral nervous disorders $(2.1 \%)$, digestive, 
urinary or genital tract diseases (4.8\%), cardiovascular diseases (1.2\%), skin and subcutaneous tissues diseases (1.9\%), and infections $(0.8 \%)$.

\section{Data collection}

The study protocol was submitted to the CNIL (90003) and DGS (2000/0107) for data privacy and ethical approval. Data collection was conducted in two stages. The case and control patients first completed a standardized self-administered questionnaire eliciting information on their socioeconomic characteristics, familial medical history, and lifetime residential and occupational histories. Regarding occupational history, each job held for at least six months was to be reported, with the job title, workplace name and business, job start and end dates, and a description of the specific tasks and products personally handled (open-ended question). The patients were also asked to report occupational exposures to a broad predefined list of agents (paints, adhesives, petrol, wood preservatives, pesticides, ionizing radiation, etc.) they could have been exposed to, and to state their average exposure frequency ('never', 'occasionally', 'at least once/week', 'every day').

The patients then underwent a face-to-face interview (average duration: 80 minutes) by trained staff using a structured standardized questionnaire eliciting personal and familial medical histories, lifestyle characteristics (smoking and alcohol, tea and coffee consumption), outdoor leisure activities and non-occupational exposures. At the end of the interview, the self-administered questionnaire was reviewed with the interviewer and, if necessary, further information was elicited using ad hoc occupational questionnaires specific to potential exposures, which will undergo further expert review by industrial hygienists.

Blood samples were obtained from the cases and controls after consent form signature and the biological specimens (sera, constitutional DNA, tumour tissue) were placed on storage.

\section{Variables analyzed}

Job titles and industries were encoded using the 1968 edition of the International Standard Classification of Occupations issued by the International Labour Organization (ILO) and the first revision of the Statistical Classification of Economic Activities in the European Community (NACE), respectively, by a trained coder, blind with respect to case/control status. Socioeconomic categories at the time of inclusion were generated from the last job held and encoded using the ILO code at the 2-digit level (0.1 to 2.1: 'scientific and administrative managers', 3.0 to 5.2: 'administrative, sales and service workers', 5.3 to 5.9 or 7.1 to 9.9 : 'factory workers', 6.0 to 6.4 : 'agricultural workers'), and were also divided into white collar (ILO codes 0.1 to 5.2 ) and blue collar (ILO codes 5.3 to 9.9) categories. Subjects having worked at least 6 month in a specific job or industry were considered exposed to that job or industry, and those who had never worked in that specific subgroup constituted the baseline category. The total duration of employment in a specific job or industry was obtained by summing the durations of all job periods in that particular job or industry. A categorical variable (unexposed, duration $<10$ 
years, duration $\geq 10$ years) was used in the analysis. Lastly, all the subjects who reported exposure, at any level, to one of the agents in the broad predefined list, were considered exposed to that agent.

\section{Data analysis}

The pair-matching used as a basis for the recruitment was broken in order to enable the whole control group to be used for the analysis of all LM types, with stratification by age (5-year age groups), gender and center. For each subgroup, HL, NHL, LPS and MM, the control group consisted in all the controls who could be included in one of the strata covered by the corresponding subgroup of cases.

The analysis of occupations consisted in 3 stages: (1) systematic screening for the occupations related to LM, which tested all the categories of occupation (2-digit ILO codes for jobs and 2-digit NACE codes for activities), with at least ten exposed subjects and at least one exposed case and one exposed control; (2) a specific analysis of farming and jobs involving solvent exposure, both corresponding to specific a priori hypotheses based on the literature. The duration of employment (never, duration $<10$ years, duration $\geq 10$ years) was used to quantify the exposures and time lags were applied to account for latency; (3) analysis of the occupational exposures derived from the self-declared checklist.

All the analyses were conducted using SAS software version 9.1 (SAS institute, Cary NC., 1989). Odds ratios (OR) and their $95 \%$ confidence intervals $(95 \% \mathrm{Cl})$ were estimated using unconditional logistic regression models including the stratification variables age, gender and center as categorical variables. The Wald test was used to test for linear trends. The duration of employment was incorporated in the model as a quantitative variable after subjects in a given category $(0$, $>0-<10, \geq 10$ years) had been allocated the median duration of employment in that category.

Analyses were conducted separately for the LM subgroups (Hodgkin's lymphoma, non-Hodgkin's lymphoma, lymphoproliferative syndrome, multiple myeloma), by gender, and for all LM taken together.

In order to check the robustness of the results, conditional logistic regressions restricted to the paired case-control samples were conducted. Polytomous logistic regressions with a 5-level nominal non-ordered response variable (Control, HL cases, NHL cases, LPS cases, MM cases) in which the common comparator was the entire control group, were also conducted.

\section{Study power}

For NHL, with power of $80 \%$ and a two-sided alpha error of $5 \%$, the size of the study sample was sufficient to evidence ORs between 1.5 and 2.7 for exposures with prevalences ranging from $2 \%$ to $20 \%$. For other subtypes of LM (HL, LPS, MM), ORs between 2.0 and 4.0 could be evidenced for the corresponding exposure prevalence. 


\section{RESULTS}

The distribution of the cases and controls by stratification variable is shown in table 1 . The use of the whole control group assigned more than 2 controls to each case in most strata, except in the youngest categories, in which HL predominated. In the latter, there was therefore a significant age difference between the HL cases and the controls. The MM cases differed from the controls with regard to gender since they did not show the male predominance observed in other lymphoid malignancies. Lastly, significant differences were also observed for the centers, mainly because the Caen hospital had a higher LPS recruitment than the other centers.

With regard to socio-demographic characteristics (Table 2), the cases and controls were similarly distributed with respect to socioeconomic category, urban/rural residential status, educational level, number of jobs held and duration of employment, except for the HL cases, who were less often factory workers and had a higher educational level than the controls.

\section{Screening}

Systematic analysis of the occupations showed significantly elevated ORs for 'farmers' (ILO code 6.1) associated with all groups of LM except LPS (OR [95\%Cl]: 1.8 [1.0-3.0], 2.9 [1.0-8.0] and 2.6 [1.3-5.5] for NHL, HL and MM, respectively). 'Agricultural and animal husbandry workers' (ILO 6.2) were associated with LPS (OR = 1.7 [1.0-2.8]) and NHL (OR $=1.5$ [1.1-2.2]). 'Transport equipment operators' (ILO 9.8) were negatively associated with NHL (OR $=0.6[0.4-1.0]$ and positively associated with LPS (OR = 1.9 [1.1-3.4]), while employment as 'cooks, waiters, bartenders' (ILO 5.3) was only associated with $\mathrm{MM}(\mathrm{OR}=2.2$ [1.0-4.7]). Screening based on industrial subgroups revealed no association for HL. The 'manufacture of chemicals and chemical products' sector (NACE 2 digit code 24) was positively linked with NHL (OR = $2.1[1.1-4.0])$ in contrast to the 'land transport; transport via pipelines' sector (NACE 60), which was negatively linked to $\mathrm{NHL}(\mathrm{OR}=0.6[0.3-1.0])$. A negative association between 'activities of households as employers of domestic staff' (NACE $95)$ and LPS was noted $(\mathrm{OR}=0.3[0.1-0.8])$. The following industrial sectors showed significant positive associations with MM: 'agriculture, hunting and related service activities' (NACE 01); 'manufacture of wearing apparel; dressing and dyeing of fur' (NACE 18); 'insurance and pension funding' (NACE 66) (ORs: 1.8 [1.0-3.1], 2.5 [1.0-6.0] and 8.4 [2.2-32.8], respectively). Conversely, the 'other business activities' sector (NACE 74) was negatively linked with MM (OR $=0.2[0.1-$ 0.9]). 


\section{Specific hypotheses}

\section{Agriculture-related jobs}

The cases had been employed in agriculture-related jobs more often than the controls (table 3). The associations tended to be more marked for employment durations greater than 10 years and for farmers (ILO 6.1), rather than for agricultural workers. For $\mathrm{NHL}$, the association was significant $(\mathrm{OR}=1.4[1.0-2.0])$ and was observed for both genders, with ORs increasing with the duration of exposure $(p$ for trend $=0.02)$. For men, significant associations were also observed with both MM and HL when the exposure duration was greater than 10 years. Similar patterns were observed for agricultural activities (NACE 01) (Table 3). The associations remained when different hypothetical lag times were considered, i.e., when the last $10,20,30$ or 40 years of employment before diagnosis or interview were considered unexposed. The associations with LPS even seemed to be strengthened as the latency period increased.

\section{Occupations involving potential solvent exposure}

The associations between solvent-related jobs and LM are shown separately for men and women in table 4. For men, the only significant association was between NHL and employment in NACE 24: 'manufacture of chemicals and chemical products' (OR = 2.6 [1.2-5.9]). For women, the occupations: 'building caretakers, char workers or cleaners' (ILO 5.51 and 5.52) were negatively associated with all $L M$, and significantly negatively associated with NHL. When all the above occupations were grouped together as solvent-exposed jobs, no association was evidenced, even for long term ( $\geq 10$ years) exposure. The numbers were too small to investigate long latency periods for most occupations, but, when the numbers were sufficient, applying various lag times did not enable any association to be evidenced.

\section{Self-declared exposure}

Table 5 reports the associations between LM and exposures from the checklist included in the self-administered questionnaire. Exposure to pesticides used for crops was significantly associated with all LM but LPS, with higher ORs for more frequent exposures. The use of wood preservatives was also associated with NHL. The associations between LM and farming were very close with (82 cases, 61 controls; $\mathrm{OR}=1.6[1.1-2.3])$ and without $(84$ cases, 64 controls; OR $=1.5$ [1.0-2.2]) self-declared exposure to pesticides, compared to subjects who had declared no exposure to pesticides and no agriculture related job. This applied to both men and women. In contrast, self-declared exposure to pesticides with no agriculture-related job was markedly associated with LM (25 cases, 11 controls; OR $=2.5$ [1.2-5.1]).

Exposure to 'paints, lacquers, varnishes' was negatively associated with LPS. No trend was observed with increasing frequency of exposure (OR: 0.5 [0.3-0.9] for occasional exposure and 0.5 [0.2-1.1] for exposure at least once per week). In order to investigate the impact of missing data, the analysis was repeated with the missing data considered no exposure for the cases and frequent exposure for the controls. The results were unchanged. The opposite classification 8 
of the missing data (missing data considered frequent exposure for the cases and no exposure for the controls) failed to reveal any association.

\section{Adjustments and sensitivity analysis}

Adjustment for urban/rural residential status, educational level, duration of employment, and number of jobs held did not change any of the results. Consistent results were obtained using conditional models, in which the LM subgroups had independent control groups, and using polytomous models. This accounts for the use of a common control group for all LM groups. Finally, the effects on the findings of each center and each reason for control admission were investigated. The results remained stable when either the centers or the reason-for-admission categories were excluded from the analysis one by one.

\section{DISCUSSION}

The main result of the present study consists in the positive associations found between most LM groups and employment in agriculture-related jobs for at least six months. The association was significant for NHL $(\mathrm{OR}=1.4[1.0-$ 2.0]) and of the same order of magnitude, although on the borderline of significance, for LPS and MM. For HL cases, the association was limited to farmers $(O R=2.9[1.0-8.0])$. Generally, associations were strengthened for exposures of duration greater than 10 years, with a significant trend for $\mathrm{NHL}$. The cases reported self-declared exposure to pesticides more often than the controls and the associations were more marked for the highest reported exposure frequencies. No association with occupational exposure to solvents was observed.

Preferential selection of farmer cases was limited since the cases were recruited in main hospitals unlikely to attract specific patient categories. Moreover, only cases living in the hospital catchment areas were recruited in order to limit potential selection on educational and socioeconomic level. The inclusion of cases was systematic and blind to the patients' occupations and educational levels. The refusal rate was low $(5.5 \%)$. In addition, there is no obvious reason for selection being similar in all the centers and the results were shown to be rugged in sensitivity analyses. Lastly, overrepresentation of farmers among the cases through selection of survivors is unlikely since inclusion took place shortly (median: 41 days) after diagnosis.

The controls were mainly recruited in orthopedic and rheumatological departments. Admissions for cancer or diseases directly related to smoking (chronic obstructive pulmonary disease, ischemic cardiovascular disease), alcohol intake (alcoholic cirrhosis) or occupation were excluded, in order to avoid artificial over-representation of some risk factors or socioeconomic categories among the controls. However, there was no restriction of control selection on past medical history, which might have under-represented particular jobs or lifestyles in the controls. Moreover, the distribution of 
socioeconomic status in the control group was very similar to that of the overall French population as determined by the National Institute for Statistics and Economic Studies in 2003.(38)

Residual selection of controls was nonetheless possible and, for that reason, we verified that the associations remained stable when groups of controls with particular reasons for admission were excluded from the analysis one-by-one. Residual selection could also have been dependent on the center but the associations were also stable after exclusion of each center from the analysis.

Lastly, although it is very credible that all LM may share common risk factors, the similar associations with agricultural professions observed for most LM subtypes may have been due to the common control group. However, the results were very similar when conditional analyses, in which each control was assigned to only one case, were conducted.

The cases and controls were interviewed in the hospitals, under the same conditions, by the same trained interviewers for each center and using standardized questionnaires, thus reducing the scope for differential misclassifications. In addition, neither the subjects nor the interviewers were aware of the specific hypotheses tested, the study being presented to both as broadly related to 'environment and health', and the person responsible for job history coding was blind to case-control status.

Non-differential misclassifications due to defective recall, common in retrospective studies, probably do not play a major role in the present results based on job history, which is more objective and easier to recall than tasks or contacts with products. The details given in the questionnaire helped code jobs and industries, and the person who coded occupations had extensive experience with the codes and coding process. However, job titles may be poor surrogates for the exposures of interest, particularly since they were aggregated at the 2-digit level. An association between solvent exposure and LM cannot be ruled out on the basis of the present results, particularly if exposures are uncommon or if associations are weak.

The analyses were performed with the stratification variables (age, gender and center) included in the models, and separately, by gender. Additional adjustments for urban/rural residence status, educational level, duration of employment and number of jobs held did not modify the results.

When different lag-time scenarios were applied, the relationship between farming-related jobs and LM was found not to be restricted to the recent exposure periods. However, most of the recent exposures had started early, and the variance of period of employment, conditionally on age and duration of employment, was too small to enable reliable conclusions. 
The screening analysis evidenced very few associations other than with agriculture-related activities, which were specifically under study, and there was no particular consistency between NACE and ILO categories. The associations may have been observed by chance, since multiple tests were run with a view to generating hypotheses.

Self-reported information on occupational exposure is probably not as reliable as information drawn from specialized interviews administered by trained interviewers. Exposures may be underreported, although frequent or long-lasting exposures are probably easier to recall than occasional exposures. Broad categories of exposure, as elicited by the selfadministered questionnaire, may lead to excessively sensitive subject classification. Non-differential misclassifications are therefore probable and may have contributed to the absence of association observed with self-reported exposures to solvents. However, the result is consistent with the absence of association observed with jobs involving solvent exposures. Non-differential misclassifications may also explain the absence of any association with pesticide exposure self-reported by farmers, although an association was observed for non-farmers. Farmers may have overlooked occasional exposures that were unremarkable in a context of common pesticide use by others.

The statistical power of the study was limited for some types of LM. The minimum detectable odds ratios for risk factors with a prevalence of about $30 \%$, like that of solvent-related jobs, were 1.7, 1.4, 1.8, 1.9, for LPS, NHL, HL and MM, respectively. Nevertheless, the estimates were close to unity and no dose-response pattern was evidenced, making the lack of power unlikely to explain the absence of association with solvent-related jobs or self -declared exposures to solvents.

The relationship between LM and occupational exposures has been investigated in many countries, with various definitions of the diseases and occupations. Overall, the results based on mortality or morbidity suggested associations, but were largely unable to elucidate the role of pesticides, antigen stimulation and animal viruses in those associations. The IARC decision to classify non-arsenical insecticide application, considered as a whole, as probably carcinogenic (group 2A) reflects the complexity of singling out a particular agent employed in farming activities.(39) Meta-analyses have estimated ORs greater than unity for agricultural occupations and NHL,(19) MM(40) and HL.(41) More recent publications on studies conducted in the USA,(13) Italy,(16) Germany(21) and Spain(18) have reported heterogeneous results with regard to the association between lifelong occupational history and LM. The pooled analysis(13) of two previous case-control studies conducted in Kansas and Nebraska $(8,10)$ reported significant associations, for men, between NHL and CLL taken as a whole and employment as a farmer $(\mathrm{OR}=1.6[1.2-2.1])$ or an agricultural activity $(\mathrm{OR}=$ 1.9 [1.4-2.6]). Analyses by LM subtype indicated that the increase in risk was particularly marked for CLL (OR $=5.7$ [3.110.7] for farmers and 8.9 [4.5-17.3] for agricultural activity). In the German study, employment as a 'farmer' (ILO 6.0-6.1) was also associated with LM, but the relationship was finally restricted to MM $(O R=9.2[2.6-33.1])$, based on a limited number of exposed subjects.(21) The Spanish data showed no association with 'ever farming', but when the farmers 11 
where subdivided into the types of farming jobs performed (e.g. crop farming, animal farming, general farming), significantly increased ORs were observed for 'general farming' for all LM subtypes. In contrast, Costantini et al. reported no association with farming.(16) The present results showed ORs of about 1.5 for all LM combined and for specific LM subtypes. The ORs are of the same order of magnitude as the estimates generated by meta-analyses. The higher estimates for farmers than for agricultural workers may be real and due to the fact that, in France where mixed farming predominates, pesticide use was usually considered an expert task that farm owners preferred not to delegate, as has been previously observed in our previous study on hairy cell leukemia.(26) A stronger association for farmers was also reported by Mester et al..(21) The present results suggest a positive trend with the duration of employment in farming. This has also been reported by Zheng et al. ,(13) while Mester et al.(21) observed the highest ORs for farming durations of less than 10 years. With respect to the exposure to pesticides itself, the current analysis is only based on the selfdeclared use of pesticides on crops, wood preservatives and treatment of buildings. Interestingly, the associations were more marked for the highest exposure frequencies.

\section{Conclusion}

The results of this study, based on occupational history and self-reported exposures, support the hypothesis that farming plays a role in most types of LM but do not evidence any association with solvent-related occupations. They also suggest that pesticides may be involved in the association.

\section{ACKNOWLEDGMENTS}

The authors are grateful to Sandra Leguyader-Peyrou, Marie-Astrid Caillet, Satya Garnier-Haoussine, Virginie Duchenet, Véronique Chaigneau, Anne-Laure Demarty, Dominique Gillet and Magali Viaud, who contributed to the interviews, and to Martine Valdes, Christine Henry, Nathalie Jourdan-Da Silva and Dominique Ridondelli, for technical assistance. The authors would also like to express their gratitude to the heads of department who helped them include patients as controls: Professors Vital, Durandeau and Le Guillou in Bordeaux, Lefevre and Le Goff in Brest, Vielpeau and Marcelli in Caen, Migaux, Duquesnois and Mazeman in Lille, Passuti and Maugars in Nantes, and Mansat and Fournier in Toulouse, and to Isabelle Soubeyran, who helped with the revision of the diagnoses, the staff of the Hematological Malignancies Registry of Gironde, who helped with the classification and coding and Professor Libersa who supported data collection in Lille. We are grateful to Andrew Mullarky for his skilful revision of the manuscript.

\section{Competing interests}

None. 


\section{REFERENCES}

1. Remontet L, Esteve J, Bouvier AM, et al. Cancer incidence and mortality in France over the period 1978-2000. Rev Epidemiol Sante Publique. 2003;51:3-30.

2. Devesa SS, Fears T. Non-Hodgkin's lymphoma time trends: United States and international data. Cancer Res. 1992;52:5432s-5440s.

3. Fisher SG, Fisher RI. The epidemiology of non-Hodgkin's lymphoma. Oncogene. 2004;23:6524-6534.

4. Banks PM. Changes in diagnosis of non-Hodgkin's lymphomas over time. Cancer Res. 1992;52:5453s-5455s.

5. Franceschi S, Dal ML, La VC. Advances in the epidemiology of HIV-associated non-Hodgkin's lymphoma and other lymphoid neoplasms. Int J Cancer. 1999;83:481-485.

6. Hjalgrim H, Askling J, Sorensen P, et al. Risk of Hodgkin's disease and other cancers after infectious mononucleosis. J Natl Cancer Inst. 2000;92:1522-1528.

7. Wotherspoon AC. Gastric lymphoma of mucosa-associated lymphoid tissue and Helicobacter pylori. Annu Rev Med. 1998;49:289-299.

8. Hoar SK, Blair A, Holmes FF, et al. Agricultural herbicide use and risk of lymphoma and soft-tissue sarcoma. JAMA. 1986;256:1141-1147.

9. Cantor KP, Blair A, Everett G, et al. Pesticides and other agricultural risk factors for non-Hodgkin's lymphoma among men in lowa and Minnesota. Cancer Res. 1992;52:2447-2455.

10. Zahm SH, Weisenburger DD, Babbitt PA, et al. A case-control study of non-Hodgkin's lymphoma and the herbicide 2,4-dichlorophenoxyacetic acid (2,4-D) in eastern Nebraska. Epidemiology. 1990;1:349-356.

11. Zahm SH, Weisenburger DD, Saal RC, Vaught JB, Babbitt PA, Blair A. The role of agricultural pesticide use in the development of non-Hodgkin's lymphoma in women. Arch Environ Health. 1993;48:353-358.

12. Schroeder JC, Olshan AF, Baric $R$, et al. Agricultural risk factors for $t(14 ; 18)$ subtypes of non-Hodgkin's lymphoma. Epidemiology. 2001;12:701-709.

13. Zheng T, Blair A, Zhang Y, Weisenburger DD, Zahm SH. Occupation and risk of non-Hodgkin's lymphoma and chronic lymphocytic leukemia. J Occup Environ Med. 2002;44:469-474.

14. Franceschi S, Barbone F, Bidoli E, et al. Cancer risk in farmers: results from a multi-site case-control study in northeastern Italy. Int J Cancer. 1993;53:740-745.

15. Amadori D, Nanni O, Falcini F, et al. Chronic lymphocytic leukaemias and non-Hodgkin's lymphomas by histological type in farming-animal breeding workers: a population case-control study based on job titles. Occup Environ Med. 1995;52:374-379. 
16. Costantini AS, Miligi L, Kriebel D, et al. A multicenter case-control study in Italy on hematolymphopoietic neoplasms and occupation. Epidemiology. 2001;12:78-87.

17. Fabbro-Peray P, Daures JP, Rossi JF. Environmental risk factors for non-Hodgkin's lymphoma: a population-based case-control study in Languedoc-Roussillon, France. Cancer Causes Control. 2001;12:201-212.

18. van $B E$, Font $R$, Cavalle $N$, et al. Exposure to non-arsenic pesticides is associated with lymphoma among farmers in Spain. Occup Environ Med. 2006;63:663-668.

19. Khuder SA, Schaub EA, Keller-Byrne JE. Meta-analyses of non-Hodgkin's lymphoma and farming. Scand J Work Environ Health. 1998;24:255-261.

20. Baris D, Silverman DT, Brown LM, et al. Occupation, pesticide exposure and risk of multiple myeloma. Scand J Work Environ Health. 2004;30:215-222.

21. Mester B, Nieters A, Deeg E, Elsner G, Becker N, Seidler A. Occupation and malignant lymphoma: a population based case control study in Germany. Occup Environ Med. 2006;63:17-26.

22. Wiklund K, Dich J. Cancer risks among male farmers in Sweden. Eur J Cancer Prev. 1995;4:81-90.

23. Nanni O, Falcini F, Buiatti E, et al. Multiple myeloma and work in agriculture: results of a case-control study in Forli, Italy. Cancer Causes Control. 1998;9:277-283.

24. Demers PA, Vaughan TL, Koepsell TD, et al. A case-control study of multiple myeloma and occupation. Am J Ind Med. 1993;23:629-639.

25. De Roos AJ, Blair A, Rusiecki JA, et al. Cancer incidence among glyphosate-exposed pesticide applicators in the Agricultural Health Study. Environ Health Perspect. 2005;113:49-54.

26. Clavel J, Hemon D, Mandereau L, Delemotte B, Severin F, Flandrin G. Farming, pesticide use and hairy-cell leukemia. Scand J Work Environ Health. 1996;22:285-293.

27. Nordstrom M, Hardell L, Magnuson A, Hagberg H, Rask-Andersen A. Occupational exposures, animal exposure and smoking as risk factors for hairy cell leukaemia evaluated in a case-control study. Br J Cancer. 1998;77:20482052.

28. Zheng T, Zahm SH, Cantor KP, Weisenburger DD, Zhang Y, Blair A. Agricultural exposure to carbamate pesticides and risk of non-Hodgkin lymphoma. J Occup Environ Med. 2001;43:641-649.

29. Chiu BC, Dave BJ, Blair A, Gapstur SM, Zahm SH, Weisenburger DD. Agricultural pesticide use and risk of $\mathrm{t}(14 ; 18)$-defined subtypes of non-Hodgkin lymphoma. Blood. 2006;108:1363-1369.

30. McDuffie HH, Pahwa P, McLaughlin JR, et al. Non-Hodgkin's lymphoma and specific pesticide exposures in men: cross-Canada study of pesticides and health. Cancer Epidemiol Biomarkers Prev. 2001;10:1155-1163.

31. Waddell BL, Zahm SH, Baris D, et al. Agricultural use of organophosphate pesticides and the risk of non-Hodgkin's lymphoma among male farmers (United States). Cancer Causes Control. 2001;12:509-517. 
32. Fritschi L, Benke G, Hughes AM, et al. Occupational exposure to pesticides and risk of non-Hodgkin's lymphoma. Am J Epidemiol. 2005;162:849-857.

33. Hardell L, Eriksson M, Nordstrom M. Exposure to pesticides as risk factor for non-Hodgkin's lymphoma and hairy cell leukemia: pooled analysis of two Swedish case-control studies. Leuk Lymphoma. 2002;43:1043-1049.

34. Eriksson M, Karlsson M. Occupational and other environmental factors and multiple myeloma: a population based case-control study. Br J Ind Med. 1992;49:95-103.

35. Baris D, Zahm SH, Cantor KP, Blair A. Agricultural use of DDT and risk of non-Hodgkin's lymphoma: pooled analysis of three case-control studies in the United States. Occup Environ Med. 1998;55:522-527.

36. Blair A, Cantor KP, Zahm SH. Non-hodgkin's lymphoma and agricultural use of the insecticide lindane. Am J Ind Med. 1998;33:82-87.

37. Purdue MP, Hoppin JA, Blair A, Dosemeci M, Alavanja MC. Occupational exposure to organochlorine insecticides and cancer incidence in the Agricultural Health Study. Int J Cancer. 2007;120:642-649.

38. INSEE. Actifs occupés selon le sexe et la catégorie socioprofessionnelle. 2005. Available at: http://www.insee.fr/fr/ffc/chifcle_fiche.asp?ref_id=NATCCF03108\&tab_id=304

39. Occupational exposures in insecticide application, and some pesticides. IARC Working Group on the Evaluation of Carcinogenic Risks to Humans. Lyon, 16-23 October 1990. In: IARC Monogr Eval Carcinog Risks Hum. France; 1991;53:5-586.

40. Khuder SA, Mutgi AB. Meta-analyses of multiple myeloma and farming. Am J Ind Med. 1997;32:510-516.

41. Khuder SA, Mutgi AB, Schaub EA, Tano BD. Meta-analysis of Hodgkin's disease among farmers. Scand J Work Environ Health. 1999;25:436-441. 


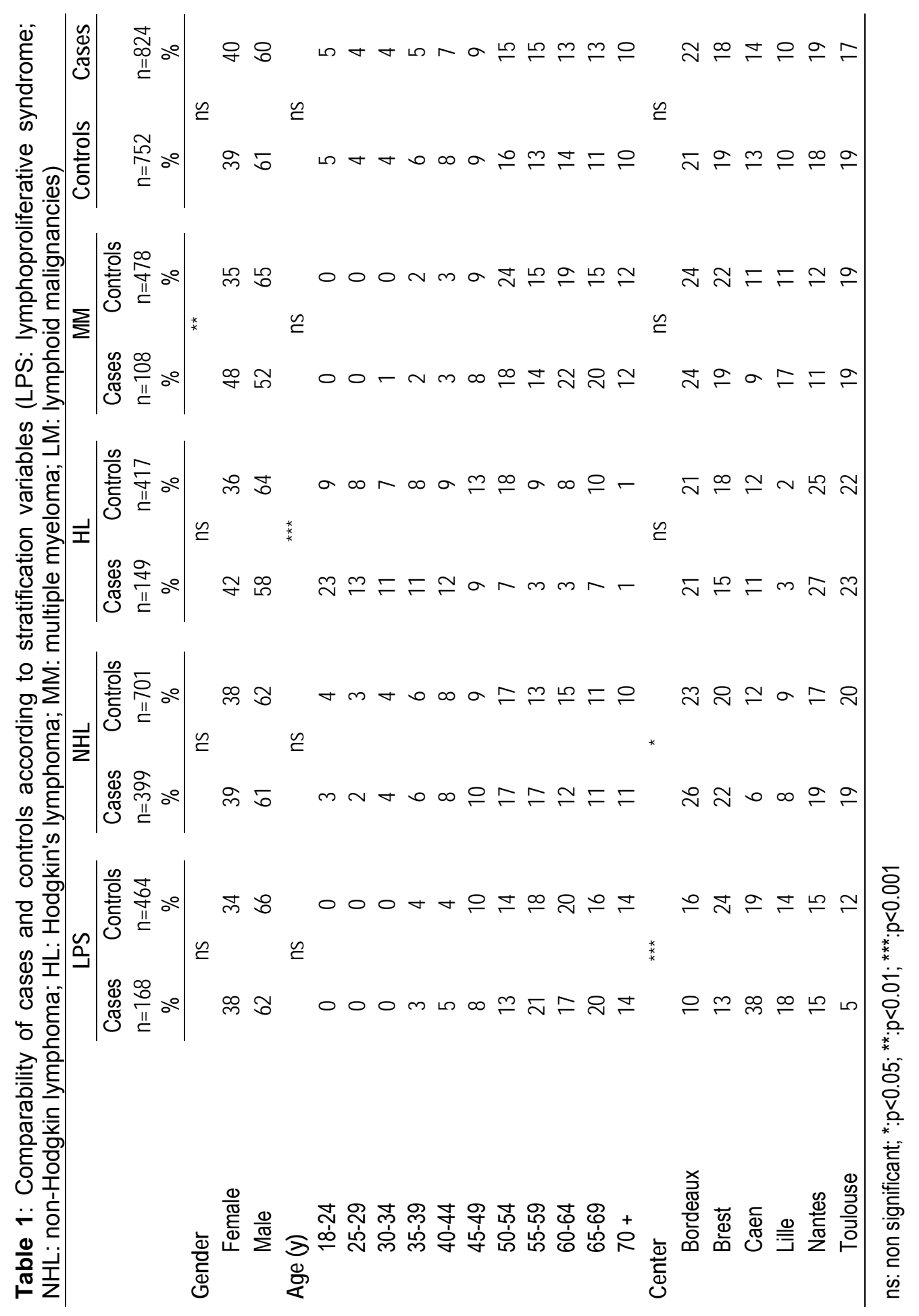




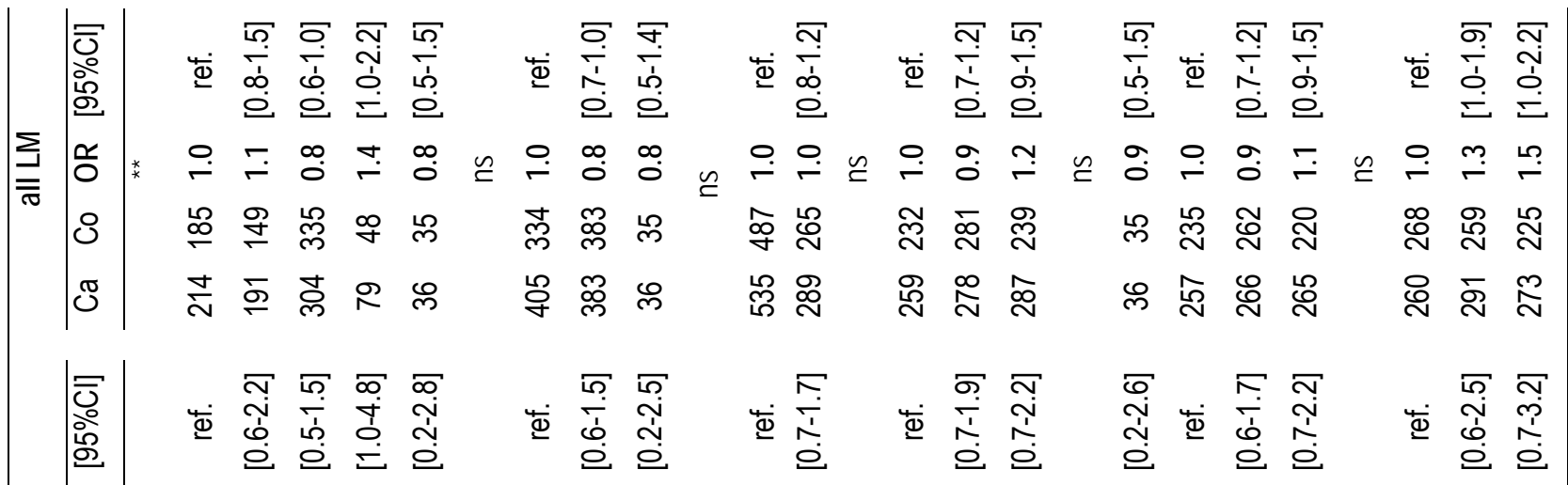
ร⿻ำ ○ $\stackrel{\infty}{\circ}$ 응 윰 ర 를

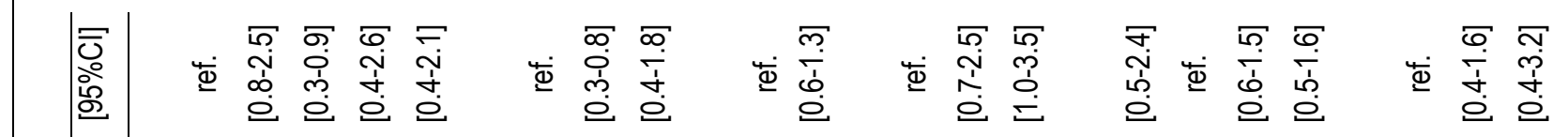
I 18 *

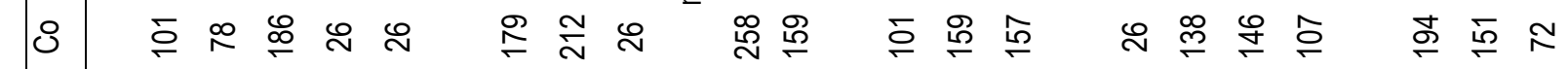

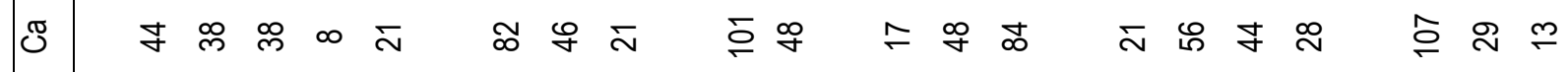
어ㅇㅜㅗ $\frac{1}{2}$ 잉

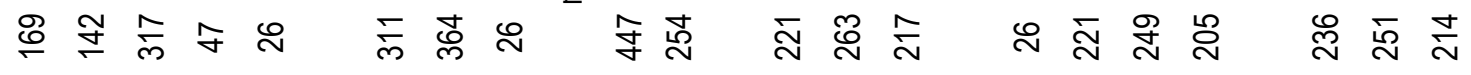

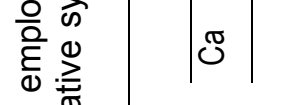

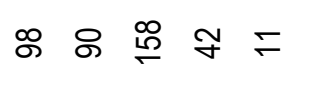

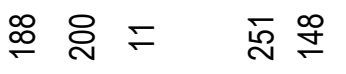

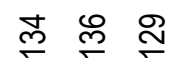

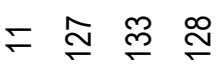
은 응 응
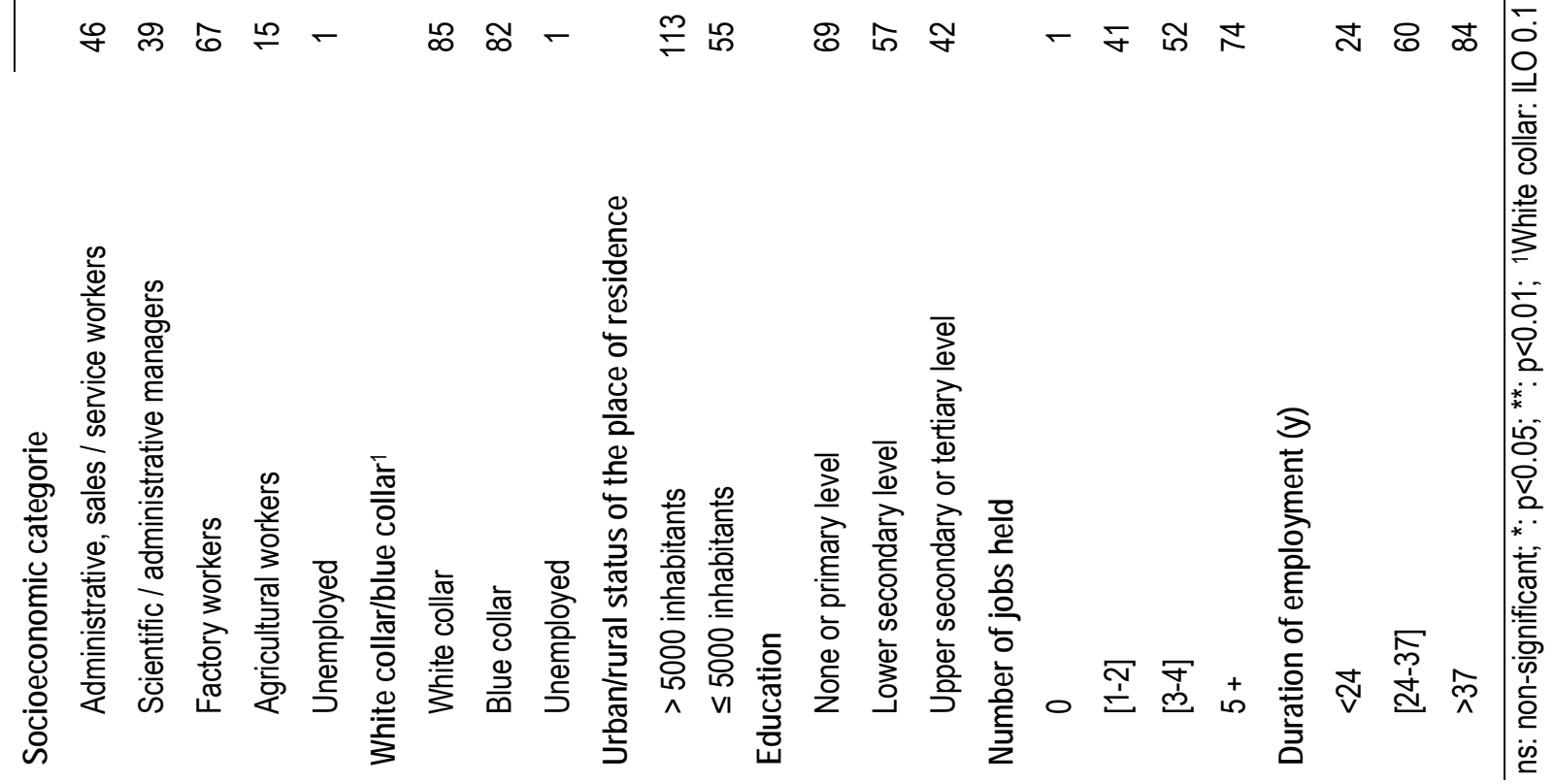


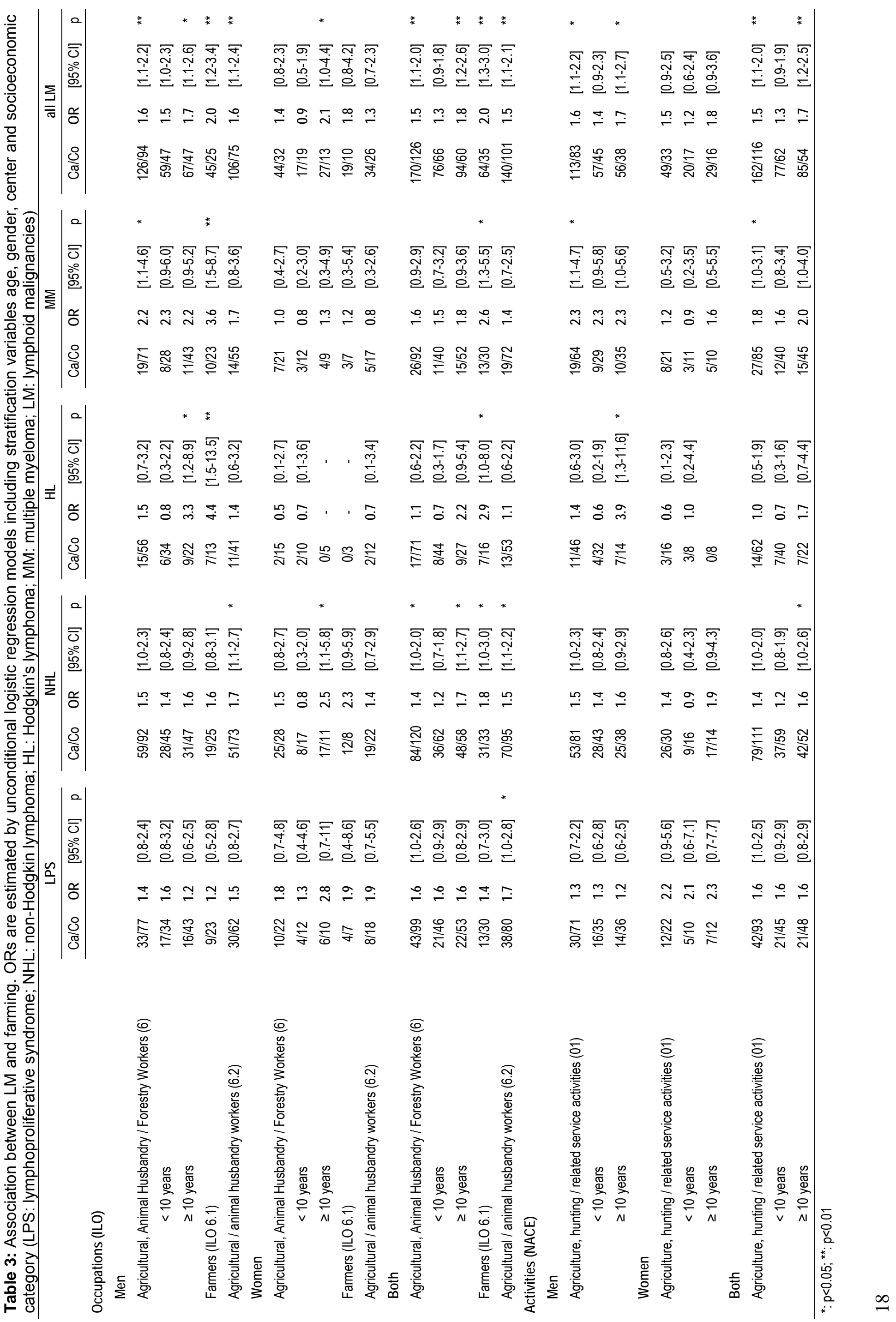




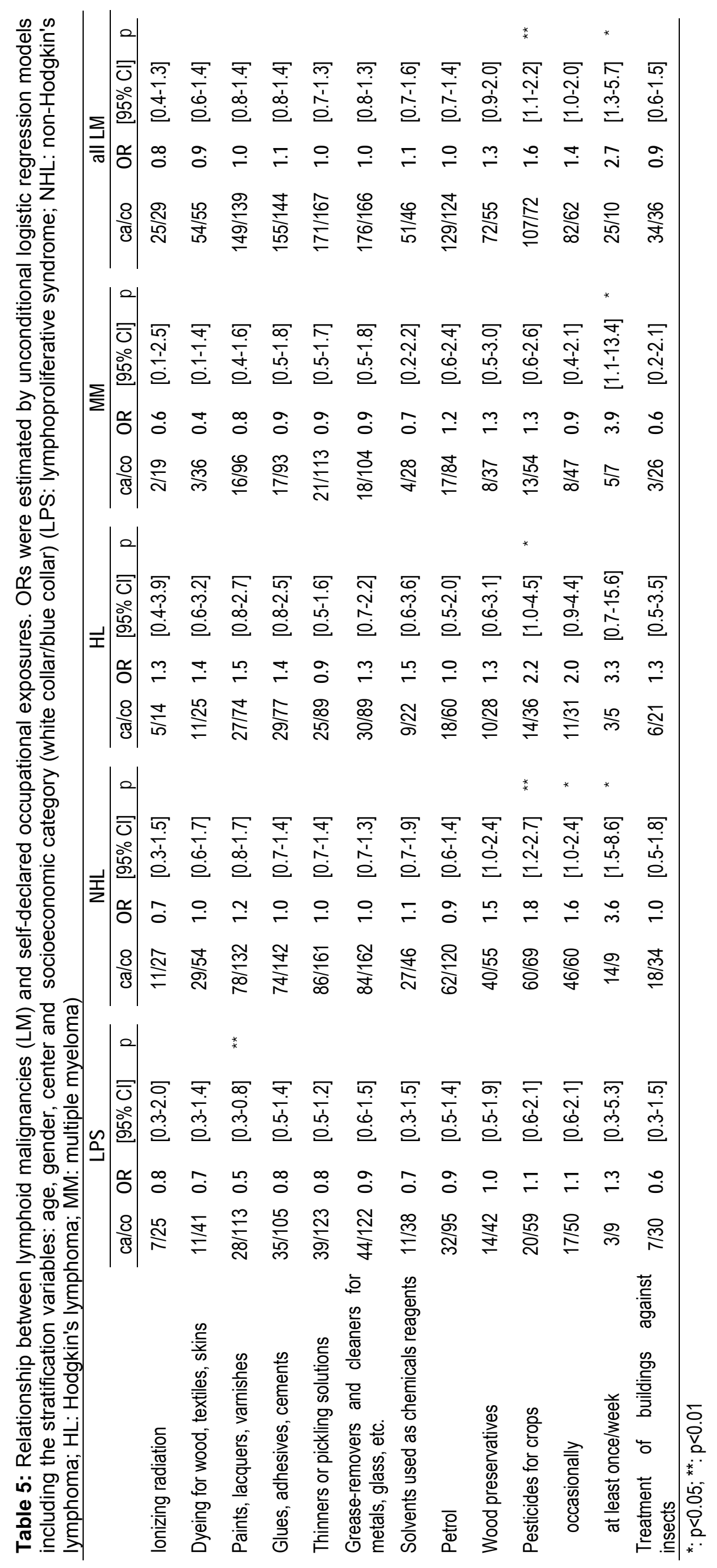

